\title{
EVOLUÇÃO NO CONHECIMENTO BIOMÉDICO E TIPIFICAÇÃO DO CRIME DE TRANSMISSÃO DO HIV
}

Rodrigo Grazinoli Garrido

Graduado em Segurança Pública. Mestre e Doutor em Ciências. Perito Criminal. Diretor do IPPGF/PCERJ. Professor Adjunto do PPGD/UCP. Professor Adjunto da FND/UFRJ. Biomédico.

Gabriela Gonçalves da Costa

Biomédica.

Esdras Eudes Medeiros

Graduando em Direito e História (UCP).

\section{RESUMO}

Com a pandemia da Síndrome da Imunodeficiência Humana Adquirida (SIDA), a partir dos anos de 1980, surgiram questões que ultrapassaram a área médica, alcançando o Direito, especialmente no que concerne a transmissão dolosa do Vírus da Imunodeficiência Humana (HIV), causador da doença. Buscou-se demonstrar como a evolução do conhecimento biomédico influenciou o Direito Penal, levando a mudanças na tipificação da conduta criminosa de transmissão do HIV. Para tanto, realizou-se pesquisa exploratória e qualitativa, a partir de documentação indireta de fontes nacionais e internacionais, bem como da legislação, doutrina e jurisprudência a respeito da conduta de transmissão dolosa do HIV. Constatou-se mudanças nas tipificações penais, seguindo a evolução do conhecimento científico. Contudo, as discussões não foram completamente pacificadas. De toda forma, o conhecimento biomédico sobre o HIV/AIDS tem possibilitado ações penais mais consistentes, baseadas em provas técnicas conclusivas.

Palavras chaves: HIV. AIDS. Transmissão. Crime.

\section{INTRODUÇÃO}

Com a pandemia da Síndrome da Imunodeficiência Adquirida (SIDA), do inglês Acquired Immune Deficiency Syndrome (AIDS), a partir dos anos de 1980, surgiram não só 
dúvidas médicas, mas sociais e jurídicas. Uma questão que, até certo ponto, ainda persiste diz respeito à tipificação do crime de transmissão dolosa do Vírus da Imunodeficiência Humana (HIV), patógeno causador da doença.

A jurisprudência e a doutrina ainda mantêm certa discordância quanto às possíveis tipificações dos crimes envolvendo a intencionalidade na transmissão do vírus. Contudo, critérios biomédicos permitem desviar o enquadramento dessa conduta do tipo penal descrito no Art. 130 do Código Penal, transmissão de doença venérea, e a possível tipificação em crime de lesão corporal grave (Art. $129 \S 2^{\circ}$, II, CP) ou perigo de contágio de moléstia grave (Art.131, CP). Da mesma forma, foi à evolução biomédica que restou por permitir a mudança da tipificação inicial dessa conduta como crime de homicídio (Art.121, CP) em sua forma tentada ou consumada e, por isso, também terá espaço nesse trabalho.

No intuito de sistematizar essas mudanças com base na evolução do conhecimento biomédico, desenvolveu-se pesquisa exploratória e qualitativa, a partir de documentação indireta de fontes secundárias nacionais e internacionais relacionadas à HIV/AIDS, bem como da legislação, doutrina e jurisprudência a respeito da conduta de transmissão dolosa do HIV.

\section{SÍNDROME DA IMUNODEFICIÊNCIA HUMANA}

No início dos anos 80, o mundo foi subitamente confrontado com uma nova e devastadora epidemia. Nesse período, os primeiros casos de AIDS foram detectados nos Estados Unidos (BARRÉ-SINOUSSI; ROSS; DELFRAISSY, 2013; CEZAR; DRAGANOV, 2014).

A epidemia - que foi inicialmente associada a homens que faziam sexo com homens, depois a usuários de drogas, pessoas que receberam transfusões de sangue e, finalmente, a população em geral - foi rapidamente se espalhando em todo o mundo, demandando pronta resposta da comunidade científica e médica (BARRÉ-SINOUSSI; ROSS; DELFRAISSY, 2013). A disseminação repentina da doença levou epidemiologistas a estabelecerem atividades de vigilância e, rapidamente, os grupos com maior risco de infecção e de transmissão da doença haviam sido identificados (BARRÉ-SINOUSSI; ROSS; DELFRAISSY, 2013).

Os primeiros resultados da pesquisa sobre o HIV surgiram em 05 de junho de 1981, quando o primeiro artigo reconhecendo um padrão de infecções oportunistas, características da AIDS, foi publicado pelo o Centro de Controle e Prevenção de Doenças (Center for 
| Revista Transgressões: ciências criminais em debate, v. 7, dezembro de 2019

desease control and prevention) (GOTTLIEB et al, 1981). O artigo descrevia cinco casos de pneumonia por Pneumocystis carinii (hoje classificado como Pneumocystis jiroveci), em Los Angeles, nos quais surgiu uma súbita e abrupta queda na condição imunológica normal (GOTTLIEB et al, 1981).

Todos os casos referiam-se a homens jovens (entre 29 e 33 anos), homossexuais, sexualmente ativos e com atuais, ou prévias, infeções pelo Vírus Citomegálico (CMV) e por Cândida $s p$. Estes homens não se conheciam, nem tinham parceiros sexuais em comum, contudo apresentavam uma idêntica história de vida (CENTER FOR DESEASE CONTROL AND PREVENTION, 1981). Desde então, muitos relatos de casos clínicos semelhantes sucederam-se. Apesar de ainda referentes a homens homossexuais, os novos relatos eram associados a outras doenças crônicas e neoplasias, como a linfadenopatia persistente generalizada (GOTTLIEB, 1981), o sarcoma de Kaposi (HYMES et al., 1981) e o linfoma não Hodgkin (ZIEGLER et al., 1982).

As análises feitas nestes doentes revelaram uma depleção acentuada no número de linfócitos T CD4+ (Cluster of differentiation 4), "maestros" supremos da imunidade mediada por células (RUBIAL-ARES et al., 2004), em contraste com a imunidade humoral, fagocitose e níveis de complemento que permaneciam aparentemente intactas (GOTTLIEB et al, 1981; MASUR et al., 1981). Essa deficiência levava à suscetibilidade aumentada a infeções por vírus e bactérias intracelulares, tumores e rejeição de aloenxertos (RUBIAL-ARES et al., 2004). Assim, a nova doença encaixava num perfil caracterizado por uma profunda imunossupressão, com infeções oportunistas associadas a tumores malignos (SELIK; CHU; WARD, 1995).

O acometimento de vários pacientes, ainda jovens e anteriormente saudáveis, por doenças, que apesar de já conhecidas, não eram comuns em associação nesse grupo, despertava a atenção e a necessidade de estudo por parte da comunidade científica, deixando cada vez mais dúvidas (BRENNAN; DURACK, 1981). Como o quadro patológico foi identificado primeiramente na população homossexual, o termo Gay Related Imunodeficiency Disease (GRID) ou Gay Compromise Syndrome foi originalmente proposto (HYMES et al., 1981; BRENNAN; DURACK, 1981). A imprensa começou por designá-la de "Gay Plage" e "Gay Cancer" até que imigrantes haitianos nos Estados Unidos da América (CENTER FOR DESEASE CONTROL AND PREVENTION, 1982), hemofílicos (R.M.; S.Y.; J.W., 1995), receptores de transfusões sanguíneas (SELIK; CHU; WARD, 1995) e outros homens e mulheres heterossexuais (CENTER FOR DESEASE CONTROL AND PREVENTION, 1983) se revelaram também como vítimas desta imunodeficiência. Assim, também foi usada a 
designação "5H" para a "nova doença", referenciando homossexuais, hemofílicos, haitianos, heroinômanos e hookers, designação em inglês para profissionais do sexo, (CEZAR; DRAGANOV, 2014).

A nova doença foi batizada oficialmente em setembro de 1982 com a designação de Síndrome da Imunodeficiência Adquirida - AIDS (CENTER FOR DESEASE CONTROL AND PREVENTION, 1982). Foram também definidos os requisitos clínicos necessários para sua caracterização: presença de doença indicativa, ou moderadamente indicativa; de depleção da imunidade mediada por células em pessoas que não tivessem outra causa subjacente; ou condição que propiciasse a instalação de doenças oportunistas, como por exemplo, o Sarcoma de Kaposi, a pneumonia por Pneumocistis carinni ou outra importante infeção oportunista (WILSON, 1995).

\section{AIDS NO BRASIL}

Na década de 80, o Brasil passava por um período de reforma no sistema de saúde, com a formulação de novas Políticas Públicas para a área. Estas visavam à extensão da cobertura da assistência e sua transparência, movimento que foi denominado Reforma Sanitária, sendo um momento de grandes conquistas para o setor da saúde pública e redemocratização do país, visto que, findava-se o regime militar (CEZAR; DRAGANOV, 2014).

Assim, o início da AIDS no Brasil foi marcado por grande mobilização, principalmente nos centros urbanos localizados na região Sudeste. Nessas áreas, apareceram os primeiros casos da doença no ano de 1982. Profissionais da saúde tentavam, sem sucesso, encontrar respostas para a nova doença (MENDONÇA; ALVES; CAMPOS, 2010).

Apesar do momento difícil vivenciado mundialmente, particularmente no Brasil, um ponto positivo surgiu: a disseminação da AIDS trouxe o envolvimento da sociedade civil exigindo acesso à informação, verbas para pesquisa e novos medicamentos, além da expansão da discussão sobre temas complexos, como direitos sexuais, direitos humanos, morte, uso de drogas, confidencialidade (GRECO, 2016).

A seguir, o quadro 1 mostra os principais acontecimentos referentes à AIDS no Brasil desde o surgimento dos primeiros casos, em 1982. Nota-se, que no país, de modo inusitado, se comparado a outros programas de controle de doenças, a luta contra a AIDS tem sido enfrentada intensamente, na defesa intransigente dos direitos humanos, com produção 
| Revista Transgressões: ciências criminais em debate, v. 7, dezembro de 2019

local e distribuição de preservativos e antirretrovirais (ARV), a implantação de rede pública de laboratórios e de serviços para cuidar das Pessoas Vivendo com HIV/AIDS (PVHA) e com financiamento para pesquisas (GRECO, 2016).

\begin{tabular}{|c|c|}
\hline \multicolumn{2}{|r|}{ Principais fatos referentes à AIDS no Brasil } \\
\hline Ano & Fatos \\
\hline 1982 & $\begin{array}{l}\text { - Primeiro caso de SIDA no Brasil (Região Sudeste), encaminhado para o } \\
\text { Hospital Emílio Ribas; }\end{array}$ \\
\hline 1983 & $\begin{array}{l}\text { - Criação do primeiro programa de controle da AIDS no Brasil, o Programa da } \\
\text { Secretaria da Saúde do Estado de São Paulo; }\end{array}$ \\
\hline 1985 & $\begin{array}{l}\text { - Fim do Regime Militar no Brasil; } \\
\text { - Criação do Programa Federal de Controle da AIDS, através da Portaria n }{ }^{\circ} 236 \\
\text { de } 2 \text { de maio; }\end{array}$ \\
\hline 1987 & - Início da utilização do Zidovudina (AZT), um antirretroviral; \\
\hline 1988 & $\begin{array}{l}\text { - Criação do Sistema Único de Saúde (SUS) Constituição Federal de 1988, } \\
\text { artigo } 196 \text { a 200); } \\
\text { - } 1^{\circ} \text { de dezembro - Dia Mundial de Luta contra a AIDS (Ministro da Saúde } \\
\text { Leonardo Santos Simão); }\end{array}$ \\
\hline 1990 & - Morte do cantor e compositor Cazuza por AIDS; \\
\hline 1992 & $\begin{array}{l}\text { - Portaria Interministerial Sheila Cartopassi n }{ }^{\circ} 796 / 922 \text { - Pró́be discriminação } \\
\text { de crianças portadoras de HIV/AIDS nas escolas; } \\
\text { - Portaria Interministerial no } 869 / 92 \text { - Proíbe testagem anti-HIV de } \\
\text { funcionários públicos federais: admissão, periódico e demissional; }\end{array}$ \\
\hline 1993 & $\begin{array}{l}\text { - AIDS no Sistema Nacional de Notificação de } \\
\text { Doenças (SINAN); }\end{array}$ \\
\hline 1996 & - Lei 9313/96 - Garante distribuição gratuita e universal de antirretrovirais. \\
\hline 1999 & - Mortalidade dos portadores de AIDS cai 50\%; \\
\hline 2001 & - Início do desenvolvimento de vacina contra HIV por cientistas da FMUSP. \\
\hline 2002 & $\begin{array}{l}\text { - Lei Estadual (São Paulo) - 11.199/02 - Proíbe discriminação dos portadores } \\
\text { do HIV/AIDS; } \\
\text { - PORTARIA No } 2104 \text { - Projeto "Nascer- Maternidades"; }\end{array}$ \\
\hline 2008 & $\begin{array}{l}\text { - Primeira fábrica estatal de preservativos do Brasil (a partir do látex de } \\
\text { seringal nativo); }\end{array}$ \\
\hline 2010 & $\begin{array}{l}\text { - PORTARIA No } 1.246 \text { MTE - Proíbe teste do HIV na admissão de } \\
\text { trabalhadores; }\end{array}$ \\
\hline 2013 & $\begin{array}{l}\text { - Teste de Profilaxia Pré-Exposição (PrEP) com o uso de antirretrovirais } \\
\text { (durante } 1 \text { ano); } \\
\text { - Mudança do protocolo de antirretrovirais em adultos (Iniciar antirretroviral } \\
\text { independente da contagem de CD4); }\end{array}$ \\
\hline 2014 & $\begin{array}{l}\text { - Mudança do protocolo de tratamento do HIV em crianças e adolescentes; } \\
\text { - Vacina HIVBr18 testada em macacos Rhesus tiveram resultados acima da } \\
\text { média, estudo realizado pela Faculdade de Medicina de São Paulo (FMUSP); } \\
\text { - LEI N }{ }^{\circ} 12.984,2 \text { de Junho- Define o crime de discriminação dos portadores } \\
\text { do HIV e doentes de AIDS; }\end{array}$ \\
\hline 2017 & - Iniciada a oferta da PrEP aos grupos de maiores riscos pelo o SUS \\
\hline
\end{tabular}


Acerca da epidemiologia, e de acordo com o último "Boletim Epidemiológico HIV/AIDS", do Departamento de Vigilância, Prevenção e Controle das Infecções Sexualmente Transmissíveis, do HIV/AIDS e das Hepatites Virais, da Secretaria de Vigilância em Saúde, do Ministério da Saúde (DIAHV/SVS/MS), publicado em 2018, foram diagnosticados 42.420 novos casos de HIV no Brasil até 2017, sendo 4.306 (10,2\%) casos na região Norte, $9.706(22,9 \%)$ casos na região Nordeste, 16.859 (39,7\%) na região Sudeste, $8.064(19,0 \%)$ na região Sul e 3.485 (8,2\%) na região Centro-Oeste (BRASIL, 2018).

Desde o início da pandemia da AIDS, até junho de 2018, foram identificados 926.742 casos de AIDS no Brasil. Porém, o número anual de casos de AIDS vem diminuindo desde 2013, quando atingiu 43.269 casos; em 2017, foram registrados 37.791 casos. A distribuição proporcional dos casos relacionados a esta doença, de 1980 a 2018, mostra uma maior concentração nas regiões Sudeste $(51,8 \%)$ e Sul $(20,0 \%)$ do total de casos; as regiões Nordeste, Norte e Centro-Oeste correspondem a 15,8\%, 6,4\% e 6,1\%, respectivamente. Vale destacar que a taxa de detecção de AIDS vem caindo no Brasil nos últimos dez anos (20072017), esta diminuição pode ser observada também nas regiões Sudeste e Sul; em 2007, as taxas de detecção dessas regiões foram de 22,0 e 32,9, passando para 17,1 e 24,1 casos por 100 mil habitantes em 2017: queda de 22,2\% e 26,7\%, respectivamente (BRASIL, 2018).

Entretanto, as regiões Norte e Nordeste apresentaram tendência de crescimento na detecção: em 2007, as taxas registradas dessas regiões foram de 16,4 (Norte) e 12,7 (Nordeste) casos por 100 mil habitantes, enquanto em 2017 foram de 23,6 (Norte) e 15,7 (Nordeste), representando aumentos de $44,2 \%$ (Norte) e $24,1 \%$ (Nordeste). A região CentroOeste apresenta taxas com comportamento mais linear (BRASIL, 2018).

A infecção pelo HIV e a AIDS fazem parte da Lista Nacional de Notificação Compulsória de doenças (Portaria $\mathrm{n}^{\mathrm{o}} 204$, de 17 de fevereiro de 2016), sendo que a AIDS é de notificação compulsória desde 1986 e a infecção pelo HIV é de notificação compulsória desde 2014. Assim, na ocorrência de casos de infecção pelo HIV ou de AIDS, estes devem ser reportados às autoridades de saúde (BRASIL, 2018).

\section{CRIMINALIZAÇÃO DA TRANSMISSÃO DO HIV: APECTOS GERAIS}

A criminalização do HIV é um termo que descreve a tipificação como um crime da conduta de pessoas com HIV em casos de transmissão e não revelação do status soropositivo. 
Nas últimas duas décadas, a criminalização do HIV emergiu como um fenômeno global. Muitos países introduziram leis criminais específicas para essa conduta e muitos outros começaram a aplicar as leis penais pré-existentes para situações de transmissão do HIV e de não divulgação (SWIFFEN, 2015).

O primeiro processo criminal relativo à transmissão do HIV ocorreu 1987, nos Estados Unidos da América. Após este, um número crescente de países aplicou as leis penais existentes e/ou criou leis específicas para os estatutos criminais, a fim de processar Pessoas Vivendo com HIV (PVHIV) que possam colocar outros indivíduos em risco (UNAIDS, 2011)

Entre outubro de 2015 e dezembro de 2018, pelo menos 913 pessoas vivendo com HIV foram presas e processadas em 49 países. O maior número de casos oi registrado na Federação Russa (pelo menos 314 casos), Bielorrússia (249), Estados Unidos da América (158), Ucrânia (29), Canadá (27), Zimbábue (16), República Tcheca (15), Reino Unido (13), França (12) e Taiwan (11) (CAMERON; BERNARD, 2019).

A Federação Russa, assim como a Bielorrússia, possui leis específicas com o objetivo de criminalizar a transmissão do HIV. A grande maioria dos casos envolve pessoas em relacionamentos heterossexuais. A lei é entendida e aplicada de uma maneira que uma pessoa que vive com HIV não apenas tem o dever de divulgar, mas também o dever de não colocar outra pessoa em risco de adquirir o HIV. A maior parte das acusações são impostas pelo Estado e são independentes do desejo do parceiro de processar e independentemente de medidas adotadas pela pessoa que vive com HIV, como usar um preservativo ou estar em tratamento com uma carga viral baixa ou indetectável (WHITBREAD; MOROZ, 2018).

A tabela 1 mostra que em vários países a lei penal é aplicada de maneira desproporcional contra as PVHIV. Foram identificados 15 pontos críticos de criminalização: países em que o número de casos era igual ou superior a 0,5 em 10.000 per capita de indivíduos diagnosticados com HIV (PEBODY, 2019).

\begin{tabular}{l|c}
\hline \multicolumn{1}{c|}{ País } & Número de casos por 10.000 PVHIV \\
\hline Bielorrússia & 139 \\
República Tcheca & 55 \\
Nova Zelândia & 10 \\
Canadá & 4 \\
Suécia & 4 \\
Federação Russa & 3
\end{tabular}


Taiwan

Ucrânia

Austrália

Suíça

Inglaterra e País de Gales

Cazaquistão

Estados Unidos da América

França

Itália

\section{3}

2

2

2

1

1

1

0,8

0,5

Tabela 1: Número de casos criminais relacionados à transmissão do HIV por 10.00 PVHIV.

Recentemente, tem ocorrido um aumento no número de casos criminais relacionados à PVHIV na África Subsaariana, no Leste Europeu e Ásia Central. Este incremento tem ocorrido, sobretudo contra mulheres, pois estas são, muitas vezes, a conhecer sua sorologia em resultado do teste rotineiro durante a gravidez e não divulgar ao parceiro devido a desigualdades, motivada pela opressão que sofrem. Além disso, essas mulheres com HIV também enfrentam a possibilidade de serem processadas por transmitir o HIV ao filho durante a gestação, nascimento ou amamentação (CAMERON; BERNARD, 2019).

$\mathrm{Na}$ verdade, em 2015, foi realizada uma pesquisa pela Rede Justiça do HIV (HIV Justice Network), na qual constatou-se que um grande número de países permite a criminalização do HIV: estes podem ter leis específicas para esta infecção, parte de leis a respeito desta contaminação (leis em que outras infecções também são abordadas), ou leis criminais e/ou de saúde pública que especificamente mencionam o HIV. A análise realizada resultou em um total de 72 países que utilizam leis específicas a fim de criminalizar o HIV, sendo que este total aumenta para 101 jurisdições quando se leva em conta separadamente as leis de criminalização do HIV nos 30 estados estadunidenses (BERNARD; CAMERON, 2016). Quanto aos processos judiciais efetivamente realizados no mundo para a revelação do HIV, exposição potencial e/ou transmissão não intencional, esses foram reportados em 61 países, ou em 105 jurisdições, quando estados individuais dos EUA e estados australianos/territórios são contados separadamente (BERNARD; CAMERON, 2016).

Os Estados Unidos da América aparecem com um dos maiores índices mundiais de processos a este grupo de indivíduos, por meio de transmissão ou exposição sexual ou não sexual, apresentando, em 24 estados, leis que visam explicitamente a não divulgação do estado HIV positivo (UNAIDS, 2011). Pelo menos 12 estados dos Estados Unidos da 
América possuem leis específicas para a criminalização do HIV para indivíduos que se envolvem em trabalhos sexuais enquanto HIV positivos, impondo penalidades reforçadas para crimes de trabalho sexual. Estas pessoas podem ser processadas mesmo que os atos realizados ofereçam pouca ou nenhuma transmissão aos seus clientes (UNAIDS, 2011).

Além de profissionais do sexo serem alvo das leis que criminalizam o HIV, outros grupos também podem ser incluídos nesta questão, como: pessoas transgênero ou transsexuais, homens que fazem sexo com homens (HSH), pessoas que usam drogas, presos e migrantes. Em 76 países - especialmente naqueles cujos governos são influenciados por interpretações conservadoras da religião - tornam criminosa a atividade sexual entre pessoas do mesmo sexo, com penas que variam de chicotadas à execução (PEREIRA; BELOQUI, 2009).

Leis punitivas focadas em populações-chave com maior risco de contaminação por HIV permanecem comuns em todo o mundo (UNAIDS, 2016). Em caso de violência sexual, na legislação de alguns países, o judiciário determina que a transmissão do HIV seja um fator agravante, atraindo penalidades mais graves (BROWN; HANEFELD; WELSH, 2009).

Sobretudo na violência sexual, as principais vítimas são mulheres e meninas. Essas representam metade da população mundial de pessoas que vivem com HIV. Leis e costumes legalmente tolerados - desde a mutilação genital até a negação de direitos de propriedade produzem profunda desigualdade de gênero; a violência doméstica também rouba poder pessoal das mulheres e meninas. Esses fatores minam a capacidade desse grupo de se proteger da infecção pelo HIV e de lidar com suas consequências (PEREIRA; BELOQUI, 2009).

Para a UNAIDS, os governos devem fortalecer e fazer cumprir as leis contra estupro (dentro e fora do casamento), e outras formas de violência contra mulheres e crianças; melhorar a eficácia dos sistemas de justiça penal em investigar e processar crimes sexuais contra estes grupos, e a igualdade de apoio e independência econômica de mulheres, incluindo, através de legislação concreta, programas e serviços (UNAIDS, 2008).

Uma questão que vale ser destacada é a fragilidade quanto ao conhecimento da rota de transmissão do HIV, pois ocorre uma questão polêmica de que muitas das leis usadas, não só pelos Estados Unidos da América, mas principalmente por este país, são vagas, inconsistentes com a ciência do HIV e excessivamente amplas - seja na própria redação ou na forma como foram interpretadas e aplicadas (BERNARD; CAMERON, 2016). A maior parte destes casos criminais foi enquadrada pelos promotores e pela mídia como sendo casos de transmissão "deliberada" ou "intencional" do HIV, quando, de fato, a maioria não envolveu intenção, nem transmissão de maneira efetiva (UNAIDS, 2011). Logo, a grande problemática 
enfrentada é que, ao invés criminalizar a transmissão real do HIV, a maior parte desses estatutos criminalizam comportamentos que podem levar ou não o risco de transmissão efetiva de HIV. E outros estatutos criminalizam a não revelação do estado HIV positivo conhecido, independentemente se um preservativo ou outros métodos eficazes de redução de risco forem usados pelo parceiro soropositivo. Na tabela 2, é demonstrada a real probabilidade de adquirir HIV de uma fonte infectada, por Lei de Exposição.

Logo, um ponto importante a respeito de leis gerais aplicadas à transmissão do HIV merece atenção, é "Falácia do Acidente". Neste caso, uma regra geral é aplicada a uma situação específica, em que esta regra seria inaplicável. Ou seja, esta inadequação penal geralmente acontece em dois passos: (1) quando há uma generalização sobre uma população; e (2) quando esta generalização é incorretamente usada para descrever um subconjunto único dessa população. Por exemplo, a declaração “os pássaros podem voar” pode ser verdadeira, mas nem sempre é verdade, há exceções. Devido a estas observações, o voo não é um fator determinante para a classificação de animais do tipo pássaros. Portanto, a aplicação de uma regra geral seria inadequada. Em uma acusação de transmissão intencional do HIV, as regras gerais podem ser injustas (WALDMAN, 2011).

\begin{tabular}{l|l}
\hline \multicolumn{1}{c|}{ Tipo de Exposição } & Risco por 10.000 exposições \\
\hline Parenteral & \\
\hline Transfusão de sangue & 9.250 \\
Compartilhamento de agulhas por drogas injetáveis & 63 \\
Percutânea & 23 \\
\hline Sexual & \\
\hline Intercurso anal receptivo & 138 \\
Intercurso anal insertivo & 11 \\
Intercurso peniano-vaginal receptivo & 8 \\
Intercurso peniano vaginal & 4 \\
Intercurso oral receptivo & Baixo \\
Intercurso oral interativo & Baixo \\
\hline Outros^ & \\
\hline Morder & Insignificante \\
Cuspir & Insignificante \\
Fluidos corporais de arremesso (Incluindo sêmen e saliva) & Insignificante \\
Compartilhamento de brinquedos sexuais & Insignificante \\
\hline Tala 2 -Probalide
\end{tabular}

Tabela 2 - Probabilidade estimada por acerto de adquirir o HIV de uma fonte infectada, por Lei de Exposição. Alguns fatores podem aumentar o risco de transmissão do HIV como doenças sexualmente transmissíveis, infecção aguda e tardia pelo HIV e alta carga viral. Já outros podem diminuir o risco como o uso de preservativo, circuncisão masculina, tratamento antirretroviral e profilaxia pré-exposição. Nenhum desses fatores é contabilizado nas estimativas apresentadas na tabela. ^ A transmissão do HIV através dessas rotas de exposição é tecnicamente possível, mas improvável e não é bem documentada Adaptada de (PATEL et al., 2014). 
Devido a isto, a Promotoria do Reino Unido, por exemplo, aprovou as "Diretrizes para análise dos processos por transmissão sexual do HIV”. Para condenar uma pessoa pela transmissão do HIV (conduta tipificada como lesão corporal grave por comportamento negligente), é necessário que exista a comprovação de que: (1) O réu sabia que tinha HIV e também que podia infectar outras pessoas, mediante determinados comportamentos; (2) Que as relações realmente ofereciam riscos de transmissão com base científica; (3) Que a vítima tem HIV; (4) Que a vítima não tinha HIV antes do relacionamento; (5) Que a vítima não teve relações sexuais, nem de outro tipo que ofereçam risco, com outras pessoas; (6) Que as variedades do vírus HIV da vítima e do acusado são compatíveis (PEREIRA; BELOQUI, 2009).

Entretanto, uma questão curiosa é que tanto os Estados Unidos da América quanto o Canadá possuem leis específicas para "agressão por fluido corporal". Nestas, incluem-se o uso de saliva, sangue, urina ou fezes, geralmente cometidos contra policiais. Por esta razão, há processos contra indivíduos infectados por HIV por agressões como cuspir, morder e/ou arranhar mesmo não sendo estes meios de transmissão do vírus (UNAIDS, 2011). Logo, o número de condenações dos EUA, quando combinadas as canadenses, somam mais do que o número de condenações feitas no resto do mundo (AVERT, 2018).

O Canadá também é um país que possui números de condenações por HIV relativamente altos. Este já fez uso de uma ampla variedade de leis criminais existentes para processar a exposição ou transmissão por HIV. Assim, este país tem um alto índice de processos criminais relacionados ao HIV, e a taxa de acusação também vem aumentando desde 1990. Atualmente, a jurisprudência canadense incluiu, no mesmo nível, a transmissão real do risco de transmissão de HIV. Isto significa que as pessoas podem ser condenadas por crimes que nenhuma transmissão real ocorreu (SWIFFEN, 2015).

O número de processos aumentou substancialmente após uma decisão do Supremo Tribunal Canadense, em 1998. Nesta, sustentou-se que, se uma pessoa soropositiva não divulgasse seu status antes de se envolver em relações sexuais consensuais, esta conduta representaria um "risco significativo" de transmissão do HIV, e, mesmo com o consentimento do parceiro, este seria inválido, tornando o sexo uma agressão, baseando-se no fato de que o "risco significativo" não foi passado de forma clara ou consistentemente definido (SWIFFEN, 2015).

Para elucidar esta questão, há um relato de caso que ocorreu em 2009, um homem canadense foi condenado em duas acusações de homicídio em primeiro grau por ter relações sexuais desprotegidas e não ter revelado o seu status soropositivo para HIV, a duas mulheres 
que mais tarde morreram de AIDS. Ele foi classificado como "criminoso perigoso" em agosto de 2011 e enfrenta tempo de prisão indefinido (UNAIDS, 2011).

Para a UNAIDS, Joint United Nations Programme on HIV/AIDS, ou, Programa Conjunto das Nações Unidas sobre HIV/AIDS, a aplicação do Direito Penal poderá acarretar riscos para a saúde pública e os direitos das PVHIV. Por causa dessas preocupações, o UNAIDS recomenda que os governos limitem a criminalização a casos de transmissão intencional, ou seja, onde uma pessoa sabe seu estado HIV positivo e age com a intenção de transmitir o patógeno e, de fato, o faz. Em outros casos, a aplicação do Direito Penal deve ser rejeitada pelos legisladores, procuradores e juízes (UNAIDS, 2008).

Vale ressaltar que no dia $1^{\circ}$ de março de 2019 ocorreu o Dia Mundial de Zero Discriminação, em que a UNAIDS destacou a necessidade urgente de ações contra leis discriminatórias, incentivando as pessoas a mudarem estes tipos de leis em seus países, a fim de acabar com o estigma e discriminação relacionados ao HIV (UNAIDS, 2019).

\section{CRIMINALIZAÇÃO DA TRANSMISSÃO DO HIV: BRASIL}

No Brasil, não há legislação para tratar do assunto ou tipo penal específico. Esta posição está de acordo com a proposta do Programa Conjunto das Nações Unidas sobre HIV/AIDS. O Programa propõe que a penalização restrinja-se à transmissão intencional, evitando-se leis específicas para o HIV e aplicando-se a lei penal geral para os casos. Deve-se também reduzir ao máximo a discricionariedade das instituições de persecução penal no que se refere à transmissão intencional (UNAIDS, 2008).

Há, contudo, o Projeto de Lei no 198/2015 que caminha em sentido contrário, isto é, busca estabelecer lei especial para a transmissão intencional, que se tornaria crime hediondo. Tal projeto está em tramitação na Comissão de Constituição e Justiça e de Cidadania (CCJ) (BRASIL, 2015). Outros três projetos encontram-se arquivados: Projeto de Lei no 130/1999, Projeto de Lei $n^{\circ}$ 276/1999 e Projeto de Lei nº 4887/2001.

Dessa forma, parece mais adequada a aplicação da lei já existente à conduta dolosa da transmissão do HIV. Contudo, tal tipificação não é tão simples. Seja pela evolução do próprio conhecimento biomédico sobre HIV/AIDS, ou mesmo pela adequação dos julgados e da doutrina, houve importante modificação da capitulação do crime nas últimas décadas. Ao partir da teoria encontrada nos manuais mais usados na formação dos bacharéis em Direito, percebe-se essas discrepâncias. 
Fato é que a infecção por HIV e a eventual doença AIDS ainda causam muito medo e estimulam posturas radicais. Greco, apesar de reconhecer que tribunais superiores têm julgado contrariamente, e que o tratamento medicamentoso tem trazido considerável sobrevida, ainda mantém o entendimento de que, por se tratar de doença incurável, no caso de transmissão dolosa do vírus, o autor deve responder pelo injusto do Art. 121 do Código Penal, caso a vítima venha a falecer, ou pelo homicídio tentado, com a manutenção da vida da vítima, visão comungada por Damásio (GRECO, 2017; JESUS, 2015).

Capez remonta o Habeas Corpus (HC) n. 9.378, julgado pelo Superior Tribunal de Justiça (STJ), ainda em 1999, considerando que, se a transmissão do vírus foi dolosa por meio de relação sexual forçada, haveria a tentativa de homicídio, ou consumado, caso seja a morte o resultado. $\mathrm{O}$ autor ainda vai além, reconhecendo o crime culposo de lesão corporal (Art. $129, \S 6^{\circ}$ ) ou homicídio (Art. $121, \S 3^{\circ}$ ), se o agente transmite o vírus sem dolo (CAPEZ, 2018).

Também há autor que considera a possibilidade de diversas tipificações para a conduta, dependendo da intenção. Assim, Bitencourt entende a possibilidade de se tratar do crime do Art. 131 (transmissão de doença grave), lesão corporal seguida de morte ou até mesmo homicídio, apesar de enfatizar o primeiro tipo (BITENCOURT, 2018).

Na verdade, posições como a de Damásio de Jesus, Rogério Greco, Fernando Capez ou mesmo Bitencourt parecem manter um entendimento que persistiu entre as décadas de 1980 e 1990 (BITENCOURT, 2018; CAPEZ, 2018; GRECO, 2017; JESUS, 2015). De acordo com Nucci, várias decisões no sentido da tipificação da transmissão do HIV/AIDS, como homicídio (tentado ou consumado), foram tomadas nas últimas décadas do séc. XX. No entanto, apesar de reconhecer que em caso concreto a contaminação com o HIV poderia levar à morte, considera que o Direito evoluiu com a dinâmica social e médica, não cabendo, atualmente, esse posicionamento. $\mathrm{O}$ autor ainda se mostra animado com as conquistas no tratamento e aposta na futura cura ou em um controle adequado que permita um convívio do portador com a doença cronificada (NUCCI, 2019).

Semelhante entendimento tem Gueiros e Japiassú. Reconhecem os autores que quando do surgimento da doença, em meados dos anos 1980, a AIDS era considerada uma doença mortal e sem qualquer controle medicinal. Portanto, a contaminação pelo vírus HIV era uma espécie de "sentença de morte". Assim, a tipificação como homicídio, ao menos tentado, se mostrava plausível.

Por outro lado, uma vez que, no início da epidemia, predominou a transmissão sexual e, até hoje, é a forma mais evidente (UNAIDS, 2016), o contágio através do ato sexual 
desprotegido ficou no imaginário e serviu para discriminar, sobretudo, trabalhadores do sexo (MOTT, 2002). Com isso, também se pensou que a transmissão dolosa do HIV deveria ser tipificada penalmente como Perigo de Contágio Venéreo (Art. 130, CP). Contudo, o escopo do dispositivo legal necessita de uma complementação explicativa para que seja definida objetivamente "Moléstia Venérea" (FILHO, 2019).

O vocábulo "venéreo" é relativo a Vênus, deusa do panteão romano, correlata à deusa Afrodite do panteão grego. Esta era a deusa do amor, da beleza, do erotismo e, dessa forma, o termo venéreo vem adjetivar aquilo que se relaciona ao sexo. Para a estipulação categórica do rol de enfermidades que o tipo penal elenca, deve-se pensar naquelas que são transmitidas necessariamente pela prática sexual: sífilis, gonorreia, herpes genital, candidíase, papiloma vírus, entre outras.

Assim, como preleciona Rogério Greco, o vírus da AIDS não pode ser considerado moléstia venérea, por conta de não ser transmitido tão somente por atos sexuais e libidinosos (GRECO, 2017). Essa posição parece estar pacificada entre os diversos autores, os quais também citam jurisprudência relacionada (BITENCOURT, 2018; CAPEZ, 2018; GONÇALVES, 2018; NUCCI, 2019).

Além disso, tem-se no núcleo do Art. 130 o verbo "expor", o que configura a consumação do ilícito penal. Portanto, para que o iter criminis (caminho do crime, em tradução livre) seja exaurido, basta que a vítima seja exposta a contágio de moléstia venérea, por meio de relações sexuais ou qualquer ato libidinoso. De toda forma, se a contaminação resulta da violência sexual, sua tipificação como condição qualificadora na forma do $\S 1^{\circ}$ do Art. 213 é indiscutível.

De toda forma, recentemente, o Superior Tribunal de Justiça (STJ), expressou sua interpretação ao caso concreto, combinando o Art. 129, § 2 , II, com o Art. 130 do Código Penal, trazendo, então, a possibilidade de o indivíduo estar concorrendo à pluralidade de crimes. Para tanto, levou em consideração o lapso temporal da ciência da portabilidade do vírus, para imputar o nexo causal ao delito de transmissão do HIV, com base no entendimento do Min. Sebastião Reis Júnior.

Crimes de lesão corporal gravíssima e perigo de contágio venéreo (arts. 129, $\S 2^{\circ}$, II, c/c o 130. Ambos do CP). A denúncia imputa ao recorrente, na qualidade de parceiro amoroso (namorado), no período de 27 de março de 2012 até aproximadamente junho do mesmo ano, na condição de portador do vírus HIV e ciente de tal condição de saúde, haver mantido relações sexuais com a vítima, sem a devida proteção - preservativo -, o que acarretou a transmissão da doença incurável. A imputação é direta, não se podendo negar a existência de lastro probatório mínimo e firme que evidencie o nexo causal, a conduta imputada e a existência de elementos 
indicativos de que o ora recorrente é seu autor (SUPERIOR TRIBUNAL DE JUSTIÇA, 2006).

Na verdade, segundo o Supremo Tribunal Federal (STF), não configura crime doloso contra a vida, a prática do ato sexual com finalidade de transmissão do vírus da AIDS (SUPREMO TRIBUNAL FEDERAL, 2010). De acordo com o voto do Min. Marco Aurélio, a propagação da síndrome de imunodeficiência não é tratada no Art. 130 e seguintes do Código Penal, ou seja, há o silêncio do legislador na menção "enfermidades sem cura", possuindo o respectivo termo abordado no $\S 2^{\circ}$, inciso II, do Art. 129 do Código Penal, independente da apresentação de sintomas para a consumação do delito (SUPERIOR TRIBUNAL DE JUSTIÇA, 2012).

Certamente, pela falta de tipo penal específico, a doutrina expressa em muitos manuais tem seguido a proposta de enquadramento da conduta em análise em um dos crimes expressos nos Arts. 129 e 131 do Código Penal. Caso a doença instale e debilite a saúde da vítima, a lesão corporal grave, ou mesmo seguida de morte, absorveria a transmissão de doença grave (NUCCI, 2019). Contudo, como estabelecido por Nélson Hungria (1979, p.411), "a gravidade da moléstia, bem como a sua contagiosidade e a relação de causalidade entre a conduta do indivíduo e o perigo concreto de contágio, tem de ser pericialmente averiguada".

Por sua vez, Juarez Tavares apresenta posição bastante radical, mas sintetiza bem o que foi proposto até aqui. Considera o autor que, em relação sexual sem proteção, a efetividade da contaminação não depende do indivíduo, mas do acaso, caracterizando "dolo eventual” (TAVARES, 2000). É importante ressaltar que na conduta de dolo eventual, que pode levar a morte da vítima, deve ser observado se a prática de relações sexuais entre a vítima e o réu, sem a devida proteção, seria suficiente para causar a morte da vítima. Para o desembargador revisor da Apelação Criminal 993.05.0700 SP, o uso desta tipificação penal não é cabível em processos criminais em que há relações sexuais consensuais, pois, embora a transmissão da doença seja controlável pelo réu, a ocorrência do resultado morte escapa ao domínio do indivíduo transmissor (PEREIRA; BELOQUI, 2009).

Além disso, Tavares retorna também à tipificação, reconhecendo que, para se determinar o enquadramento da conduta em homicídio ou lesões corporais graves, é preciso a "vontade de realização da ação e do resultado, deve referir-se a uma ação imediata, e não a uma ação que, por sua cronicidade, conduza à morte. Portanto, só pode haver crime de lesão corporal grave e não homicídio" (TAVARES, 2000, p. 290). 
Em se tratando de transmissão do vírus HIV, em caso recente, foi julgado pelo STF em 2018. Neste, foi negado o habeas corpus impetrado em favor do indivíduo acusado de manter relações sexuais com a devida ciência de portabilidade do vírus HIV, possuindo dolo de transmiti-lo, sendo denunciado pela prática de lesão corporal grave, com fulcro no Art.129, $\S 10$, do Código Penal. De acordo com o Min. Gilmar Mendes, a prisão atende todos os requisitos dos dados concretos e reconhece a periculosidade do autor do ilícito em desfavor do número de vítimas identificadas, justificando a permanência da prisão preventiva, fundamentada pelo resguardo da ordem pública.

Qualquer que seja a tipificação, tratam-se de crimes que deixam vestígios e dependem, para a determinação da causalidade, ou mesmo da gravidade, de exames técnicos periciais. Contudo, curiosamente, parece não ser esta a realidade nas ações penais relacionadas. Em etnografia realizada por Nelvo, em que remonta através de documentos dois “casos jurídicos de transmissão do HIV", nos quais não havia violência sexual envolvida na conduta, o autor percebe que não se buscaram evidências científicas que determinassem a linha de transmissão do vírus (NELVO, 2017).

\section{CONSIDERAÇÕES FINAIS}

A pesquisa permitiu constatar mudanças nas tipificações penais que acompanharam, mesmo que mais lentamente, a evolução do conhecimento científico acerca do HIV/AIDS. A infecção, que inicialmente era vista como uma pena de morte, hoje, ainda que sem cura, apresenta prognóstico melhor, pois a terapia farmacológica antirretroviral permitiu ao infectado o convívio com uma doença crônica manejável, aumentando a sobrevida dos indivíduos infectados pelo HIV.

Contudo, do ponto de vista jurídico penal, ainda há discussões acerca da tipificação do crime relacionado à transmissão dolosa do HIV. Alguns países no exterior apresentam leis específicas, tipificando esta conduta. Outros, como o Brasil, utilizam dispositivos de leis gerais com o intuito de penalizar esta atitude. Além disso, o Direito Penal brasileiro, finalístico, reconhece que o crime pelo o qual o agente deverá responder dependerá do resultado final da ação, diante da conduta intencional, no caso em estudo, e consciente do agente. Assim, faz-se sempre necessário a minuciosa análise da influência da conduta para se determinar o fato como típico. 
Fato é que com o progresso no conhecimento biomédico sobre o HIV/AIDS, as ações penais atualmente movidas também se tornaram mais consistentes, haja vista o crescimento dos recursos científicos para análise do caso concreto, que são usados de forma a produzirem consistentes provas técnicas. Portanto, pode ser determinado se realmente há crime, e qual o caminho percorrido pelo agente criminoso. Assim, vem tornando-se possível precisar, no caso concreto, autoria e materialidade do fato, gerando maior confiabilidade para o dever de punir do Estado.

\section{REFERÊNCIAS}

BARRÉ-SINOUSSI, Françoise; ROSS, Ana Laura; DELFRAISSY, Jean-François. Past, present and future: 30 years of HIV research. Nature Reviews Microbiology, v. 11, n. 12, p. 877-883, 2013. Disponível em: <https://www.nature.com/articles/nrmicro3132>. Acesso em: 06 out. 2019.

BERNARD, Edwin; CAMERON, Sally. Advancing HIV Justice 2: Building momentum in global advocacy against HIV criminalisation. HIV Justice Network and the Global Network of People Living with HIV (GNP+), 2016. Disponível em: <http://www.hivjustice.net/advancing2>/. Acesso em: 06 out. 2019.

BITENCOURT, Cezar Roberto. Tratado de direito penal - v. 2: parte especial (arts. $121 \mathrm{a}$ 154-B): crimes contra a pessoa. 18. ed. São Paulo: Saraiva, p. 584, 2018.

BRASIL, Ministério da Saúde - Secretaria de Vigilância em Saúde. Boletim Epidemiológico HIV Aids Julho de 2017 a junho de 2018. Boletim epidemiológico. AIDS, Brasília, 2018, 72 p. Disponível em: <http://www.aids.gov.br/pt-br/pub/2018/boletim-epidemiologico-hivaids2018>. Acesso em: 06 out. 2019.

BRASIL. PL 198/2015. Torna crime hediondo a transmissão deliberada do vírus da AIDS. Apresentação em 04/02/2015. Brasília: Câmara dos Deputados. Disponível e: https://www.camara.leg.br/proposicoesWeb/fichadetramitacao?idProposicao=945940. Acesso em: 06 out. 2019. 
BRENNAN, Robert O; DURACK, David T. GAY COMPROMISE SYNDROME. The Lancet Infectious Diseases, p. 1338-1339, 1981. Disponível em:

<https://www.thelancet.com/journals/lancet/article/PIIS0140-6736(81)91352-0/fulltext>. Acesso em: 06 out. 2019.

BROWN, Widney; HANEFELD, Johanna; WELSH, James. Criminalising HIV transmission: punishment without protection. Reproductive Health Matters, v. 17, n. 34, p. 119-126, 2009. Disponível em: <https://www.tandfonline.com/doi/full/10.1016/S0968-8080(09)344778>. Acesso em: 06 out 2019.

CAMERON, S; BERNARD EJ. Advancing HIV Justice 3: Growing the global movement against HIV criminalisation. HIVJustice Network, Amsterdam, Maio 2019.

CAPEZ, Fernando. Curso de Direito Penal: parte especial. v.2, 18. ed., São Paulo: Saraiva, 2018.

CENTER FOR DESEASE CONTROL AND PREVENTION - CDC. Pneumocystis pneumonia - Los Angeles. MMWR Weekly Report, 1981. Disponível em: <https://www.cdc.gov/mmwr/preview/mmwrhtml/june_5.htm>. Acesso em 06 out. 2019.

CENTER FOR DESEASE CONTROL AND PREVENTION - CDC. Opportunistic Infections and Kaposi's Sarcoma among Haitians in the United States. MMWR Morb Mortal Wkly Rep, 1982. Disponível em: <https://www.cdc.gov/mmwr/preview/mmwrhtml/00001123.htm>. Acesso em 06 out. 2019.

CENTER FOR DESEASE CONTROL AND PREVENTION - CDC. Acquired immune deficiency syndrome (AIDS) in prison inmates--New York, New Jersey. MMWR Morb Mortal Wkly Rep, 1983. Disponível em: <https://www.cdc.gov/mmwr/preview/mmwrhtml/00001223.htm>. Acesso em: 06 out 2019.

CEZAR, V. M.; DRAGANOV, P. B. A História e as Políticas Públicas do HIV no Brasil sob uma Visão Bioética History and HIV From Public Policy in Brazil under a Bioethics Vision. Ensaios Cienc, v. 18, n. 3, p. 151-156, 2014. 
FILHO, José Nabuco. Perigo de contágio venéreo (art. 130). Disponível em: $<$ http://josenabucofilho.com.br/home/direito-penal/parte-especial/perigo-de-contagiovenereo-art-130/> . Acesso em: 06 out. 2019.

GOTTLIEB, Michael S. et al Pneumocystis carinii pneumonia and mucosal candidiasis in previously healthy homosexual men: evidence of a new acquired cellular immunodeficiency.

N. Engl. J. Med. 305, 1425-1431, 1981. Disponível em:

<https://www.nejm.org/doi/full/10.1056/NEJM198112103052401?url_ver=Z39.88-

2003\&rfr_id=ori\%3Arid\%3Acrossref.org\&rfr_dat=cr_pub\%3Dpubmed $>$. Acesso em: 06 out. 2019.

GRECO, Dirceu Bartolomeu. Trinta anos de enfrentamento à epidemia da Aids no Brasil, 1985-2015. Ciência \& Saúde Coletiva, v. 21, n. 5, p. 1553-1564, 2016. Disponível: <http://www.scielo.br/pdf/csc/v21n5/1413-8123-csc-21-05-1553.pdf>. Acesso em: 06 out. 2019.

GRECO, Rogério. Curso de Direito Penal: parte especial, volume II: introdução à teoria geral da parte especial: crimes contra a pessoa. 14. ed. Niterói: Imeptus, 2017.

HYMES, Kenneth B. et al. Kaposi's Sarcoma in Homosexual Men-a Report of Eight Cases. The Lancet. V. 313, 8247, p. 598-600, 1981. Disponível em: <https://www.thelancet.com/journals/lancet/article/PIIS0140-6736(81)92740-9/fulltext>. Acesso em: 06 out. 2019.

JESUS, Damásio de. Direito penal, $2^{\circ}$ volume: parte especial ; Crimes contra a pessoa a crimes contra o patrimônio. $35^{\circ}$. ed. São Paulo: Saraiva, 2015.

MASUR Henry, et al. An outbreak of community-acquired Pneumocystis carinii pneumonia: initial manifestation of cellular immune dysfunction. N Engl J Med., 305, p.1431-1438, 1981. Disponível em:

<https://www.nejm.org/doi/full/10.1056/NEJM198112103052402?url_ver=Z39.882003\&rfr_id=ori:rid:crossref.org\&rfr_dat=cr_pub\%3dpubmed>. Acesso em: 06 out. 2018. 
Claudio. Emprendedorismo institucional en la emergencia del campo de políticas públicas en VIH/sida en Brasil. RAE electron., São Paulo, v. 9, n. 1, June 2010 . Disponível em: $<$ http://www.scielo.br/scielo.php?script=sci_arttext\&pid=S167656482010000100007\&lng=en\&nrm=iso>. Acesso em: 06 out. 2019.

MOTT, Luiz. Transmissão dolosa do HIV-Aids: relatos da imprensa brasileira. Piracicaba: Impulso: Revista de Ciências Sociais e Humanas, v. 13, n³2, p. 157-174, 2002.

NELVO, Romário Vieira. Enredo das condenações: uma etnografia entre documentos e "justiça" acerca de casos de transmissão do HIV / The plot of condemns: an ethnogaphy between documents and "justice" about cases of HIV transmission. Idealogando: Revista de Ciências Sociais da UFPE, [S.1.], v. 1, n. 2, p. 102-121, nov. 2017. ISSN 2526-3552. Disponível em: <https://periodicos.ufpe.br/revistas/idealogando/article/view/11869>. Acesso em: 06 out. 2019.

NUCCI, Guilherme de Souza. Curso de Direito Penal: parte especial: arts. 121 a 212 do Código Penal. $3^{\text {a }}$ ed. Rio de Janeiro:Forense, 2019.

PATEL, Pragna, et al. Estimating per-act HIV transmission risk: A systematic review. Aids, v. 28, n. 10, p. 1509-1519, 2014. Disponível em: <https://www.ncbi.nlm.nih.gov/pmc/articles/PMC6195215/>. Acesso em: 06 out. 2019.

PEBODY, Roger. HIV criminalisation cases recorded in 72 countries, including 49 in the last four years. HIV \& Criminal Law. Disponível em: <https://www.aidsmap.com/news/jun2019/hiv-criminalisation-cases-recorded-72-countries-including-49-last-four-years>. Acesso em: 19 dez. 2019.

PEREIRA, Claudio; BELOQUI, Jorge. Breve Estudo a Respeito da Criminalização da Transmissão do Hiv/Aids nas Relações Consensuais. Direitos Humanos criminalização?. 2009, 16p. Disponível em: <http://www.giv.org.br/Publica\%C3\%A7\%C3\%B5es/CartilhaDireitos-Humanos-Criminaliza\%C3\%A7\%C3\%A3o-da-Transmiss\%C3\%A3o.pdf >. Acesso em: 06 out. 2019.

RUBIAL-ARES Beatriz et al. Interacciones del Virus de la Imunodeficiência humana con 
Células del Sistema Inmune. In: RABINOVICH Andrián Gabriel (ed). Imunopatologia molecular: nuevas fronteras de la medicina: um nexo entre la investigación biomedical y la prática clinica. Argentina: Panamericana. 2004, p. 323-329.

SELIK RICHARD M; CHU SUSAN Y; WARD JOHN W. Trends in infectious diseases and cancers among persons dying of HIV infection in the United States from 1987 to 1992. Ann Intern Med. 15;123(12), p.933-936, 1995. Disponível em:

$<$ https://www.annals.org/article.aspx? volume=123\&issue=12\&page=933>. Acesso em 06 out. 2019 ,

\section{SUPREMO TRIBUNAL FEDERAL. Habeas Corpus: HC 98.712/SP, Relator Ministro} Marco Aurélio, $1^{\text {a }}$ Turma 05/10/2010. Disponível em:

$<$ http://redir.stf.jus.br/paginadorpub/paginador.jsp?docTP=AC\&docID=617972>. Acesso em: 06 out. 2019.

\section{SUPERIOR TRIBUNAL DE JUSTIÇA. Recurso Ordinário em Habeas Corpus: RHC} 58.563/RJ, Relator Ministro Sebastião Reis Junior. 6a T., DJ e 08/09/2006. Disponível em: $<$ https://stj.jusbrasil.com.br/jurisprudencia/387032029/recurso-ordinario-em-habeas-corpusrhc-58563-rj-2015-0086590-7/inteiro-teor-387032046>. Acesso em: 06 out. 2019.

\section{SUPERIOR TRIBUNAL DE JUSTIÇA. Habeas Corpus: HC 160.982/DF, Relatora}

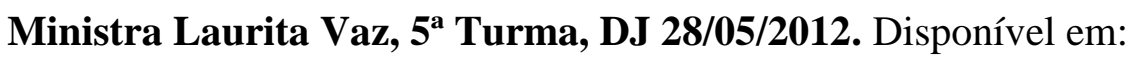
<https://stj.jusbrasil.com.br/jurisprudencia/22560449/habeas-corpus-hc-165089-df-20100044021-3-stj/inteiro-teor-22560450>. Acesso em: 06 out. 2019.

SWIFFEN, A. Bio-Crime: the criminalization of HIV in Canada. Law \& Governance, v. 17, n. 5 , p. 1-6, 2015.

TAVARES, Juarez. Teoria do injusto penal. Belo Horizonte: Del Rey: 2000

UNAIDS. Criminalization of HIV transmission. Police Brief, n. December, Genebra, 2008. Disponível em:

<http://data.unaids.org/pub/manual/2008/jc1601_policy_brief_criminalization_long_en.pdf>. Acesso em: 06 out. 2019 
UNAIDS - JOINT UNITED NATIONS PROGRAMME ON HIV/AIDS. Criminalisation of HIV non-disclosure, exposure and transmission: Background and current landscape. $n$. September 2011, Genebra, 2011, 44p. Disponível em: <https://www.unaids.org/sites/default/files/media_asset/JC2322_BackgroundCurrentLandsca peCriminalisationHIV_en.pdf>. Acesso em: 06 out. 2019.

UNAIDS - JOINT UNITED NATIONS PROGRAMME ON HIV/AIDS. AIDS by the numbers, 2016. Disponível em:

<https://www.unaids.org/sites/default/files/media_asset/AIDS-by-the-numbers-2016_en.pdf>. Acesso em: 06 out. 2019.

\section{UNAIDS - JOINT UNITED NATIONS PROGRAMME ON HIV/AIDS. Programme on} HIV/AIDS. 2019. Disponível em: <https://unaids.org.br/> . Aceso em: 06 out. 2019.

WALDMAN, Ari Ezra. Exceptions: The Criminal Law's Illogical Approach to HIV-Related Aggravated Assaults. Virginia Journal of Social Policy and the Law, v. 183, p. 550-605, 2011. Disponível em:

$<$ https://digitalcommons.nyls.edu/cgi/viewcontent.cgi?article=1692\&context=fac_articles_ch apters>. Acesso em: 06 out. 2019.

WHITBREAD, Jessica; MOROZ, Svitlana. Regional Eastern Europe and Central Ásia. HIV Justice Network, Amsterdam, 2018

WILSON, R. Epidemiology of AIDS. Optometry and Vision Science, v. 72, n. 5, p. 294 295, 1995. Disponível em:

<https://journals.lww.com/optvissci/Abstract/1995/05000/Epidemiology_of_AIDS.2.aspx> Acesso em: 07 out. 2019.

ZIEGLER JL. et al. Undifferentiated Non-Hodgkins Lynfoma among Homosexual Males. MMWR Morbid Mortal Wkly Rep [online], 1982. Disponível em: < https://www.cdc.gov/mmwr/preview/mmwrhtml/00001104.htm?>. Acesso em: 07 out. 2019. 
ZUCCHI, E. M. et al. Da evidência à ação: desafios do Sistema Único de Saúde para ofertar a profilaxia pré-exposição sexual (PrEP) ao HIV às pessoas em maior vulnerabilidade.

Cadernos de Saúde Pública [online], v. 34, n. 7, p. 1-16, 2018. Disponível em:

$<$ http://www.scielo.br/scielo.php?script=sci_arttext\&pid=S0102-

311X2018000703001\&lng=pt\&nrm=iso>. Acesso em: 07 out. 2019.

\title{
EVOLUTION IN BIOMEDICAL KNOWLEDGE AND TYPIFICATION OF HIV TRANSMISSION CRIME
}

\begin{abstract}
With the Acquired Human Immunodeficiency Syndrome (AIDS) pandemic, since the 1980s, questions have emerged that surpassed the medical field, reaching the Law, especially regarding the malicious transmission of the Human Immunodeficiency Virus (HIV), which causes the disease. disease. We sought to demonstrate how the evolution of biomedical knowledge influenced criminal law, leading to changes in the typification of criminal conduct of HIV transmission. To this end, exploratory and qualitative research was conducted, based on indirect documentation from national and international sources, as well as legislation, doctrine, and jurisprudence regarding the conduct of intentional transmission of HIV. Changes in criminal typifications were observed, following the evolution of scientific knowledge. However, the discussions were not completely pacified. In any case, biomedical knowledge about HIV / AIDS has enabled more consistent criminal actions based on conclusive technical evidence.
\end{abstract}

Keywords: HIV. AIDS. Transmission. Crime. 